\title{
Vertebral Localization of Multifocal Skeletal Tuberculosis: Case Report and Literature Review
}

\author{
Fulbert Kouakou, Alban Slim Mbende, André Tokpa, Nicole Adou, Dominique N’Dri Oka* \\ Neurosurgery Unit, Yopougon Teaching Hospital, Ivory Coast \\ Email: *ndriokad@gmail.com
}

How to cite this paper: Kouakou, F., Mbende, A.S., Tokpa, A., Adou, N. and N'Dri Oka, D. (2017) Vertebral Localization of Multifocal Skeletal Tuberculosis: Case Report and Literature Review. Open Journal of Modern Neurosurgery, 7, 11-18.

https://doi.org/10.4236/ojmn.2017.72002

Received: December 21, 2016

Accepted: April 10, 2017

Published: April 13, 2017

Copyright (c) 2017 by authors and Scientific Research Publishing Inc. This work is licensed under the Creative Commons Attribution International License (CC BY 4.0).

http://creativecommons.org/licenses/by/4.0/

\begin{abstract}
Multifocal skeletal tuberculosis is a rare condition. The diagnosis is difficult and the treatment is delayed in the vast majority of cases. A 30-year-old immunocompetent jobless male complained of thoracic and lumbar spine pain for several weeks, associated with progressive weight loss without fever. Neurological examination was normal. CT scanning demonstrated hypodense multifocal lesions of the spine and the hip. Vertebroplasty was performed successfully. But a pathological examination of the biopsy of spinal lesions was not conclusive. One month later, the patient developed an acute spinal cord compression syndrome. Emergency decompression surgery was performed, which demonstrated the purulent epidural abscess and osteolysis. The pathological examination was in favor of tuberculosis. Despite surgical stabilization and cementoplasty, anti-TB therapy and kinesitherapy, the patient was still significantly limited a few months later with a flaccid paraplegia. TB infection was cleared at the end of the two-phase regimen. Atypical tuberculosis ormultifocal TB poses diagnostic problems especially with metastases, malignant lymphoma, and multiple myeloma. We report this rare case of mutifocal skeletal tuberculosis to show the place of vertebroplasty in the management of spinal tuberculosisor if there is indeed a potential role that vertebroplasty could have played in spreading spinal lesions. The patient was informed that non identifying information from the case would be submitted for publication, and he provided consent.
\end{abstract}

\section{Keywords}

Multifocale, Vertebroplasty, Skeletal Tuberculosis, Diagnosis, Treatment

\section{Introduction}

Vertebral tuberculosis is the typically spondylodiscitis. Progress in medical im- 
aging technology revolutionised the understanding and the description of multifocal tuberculosis. Tuberculous spondylitis is less common and yet the most dangerous form of skeletal tuberculosis [1]. There has been a resurgence of $\mathrm{My}$ cobacterium tuberculosis worldwide in recent years and the future looks gloomy, given the increase incidence of HIV [2] [3]. Multifocal bone involvement seldom men counted in the developed world, is still reported in countries where tuberculosis remains endemic [4]. Multifocal skeletal tuberculosis is a rare condition which makes the diagnosis difficult and the treatment is delayed in the vast majority of cases. We report this rare case of a 30-year-old immunocompetent jobless male with vertebral localization of multifocale skeletal tuberculosis. It is the authors' view that this case raises issues related to the diagnosis and management of multifocal skeletal tuberculosis, and a potential role that vertebroplasty could have played in spreading spinal lesions.

\section{Case report}

A 30-year-old immunocompetent jobless male complained of thoracic and lumbar spine pain for several weeks, associated with progressive weight loss without fever. We failed to acertain a history of tuberculosis (TB) in the patient's inner circle, but a PPD (purified protein derivative) test was positive. Neurological examination was normal apart from percussion tenderness over his thoracic and lumbar spinous processes. Spinal MRI showed hypointense and hyperintense lesions on $\mathrm{T} 1$ weighted and $\mathrm{T} 2$ weighted imaging respectively, without obvious cord compression syndrome. Unfortunately, due to some technical issues in the MRI suite, only bone windows were made available despite repeated requests from the neurosurgical team. A panoramic scan of the axial skeleton showed multiple skeletal lesions including the spine and the pelvic bone which were hypodense (Figure 1). Protein electrophoresis was normal. Top differential diagnoses for these multifocal skeletal lesions are tuberculosis, histoplasmosis, metastasis, malignant myeloma and osseous primitive tumour (Figure 2). Local current protocols for skeletal TB management require at least three strong criteria (history of TB in the inner circle, positive PPD test and a positive biopsy for mycobacteria) before anti-TB drugs are delivered to the patient. Therefore, an open kyphoplasty (for biopsy, pain relief and instability correction) was warranted but in our case, economic strain on patient's financies compounded with inadequate hospital equipment and the lack of a reliable blood bank, meant that the procedure could not be performed. As a result, the patient condition deteriorated with a 3/5 paraparesis whilst waiting for necessary funding to undergo any procedure (percutaneous sampling or open biopsy and stabilisation) which could have led to an early definite diagnosis. Urgent vertebroplasty was indicated instead, given its reduced cost and accessibility in the region. The immediate postoperative course was uneventful and the patient was discharged a few days later pending further results from the examination of spinal lesions. But a pathological examination of the biopsy of spinal lesions was not conclusive. We could not unfortunately acertain from the laboratory report, why in an endemic 

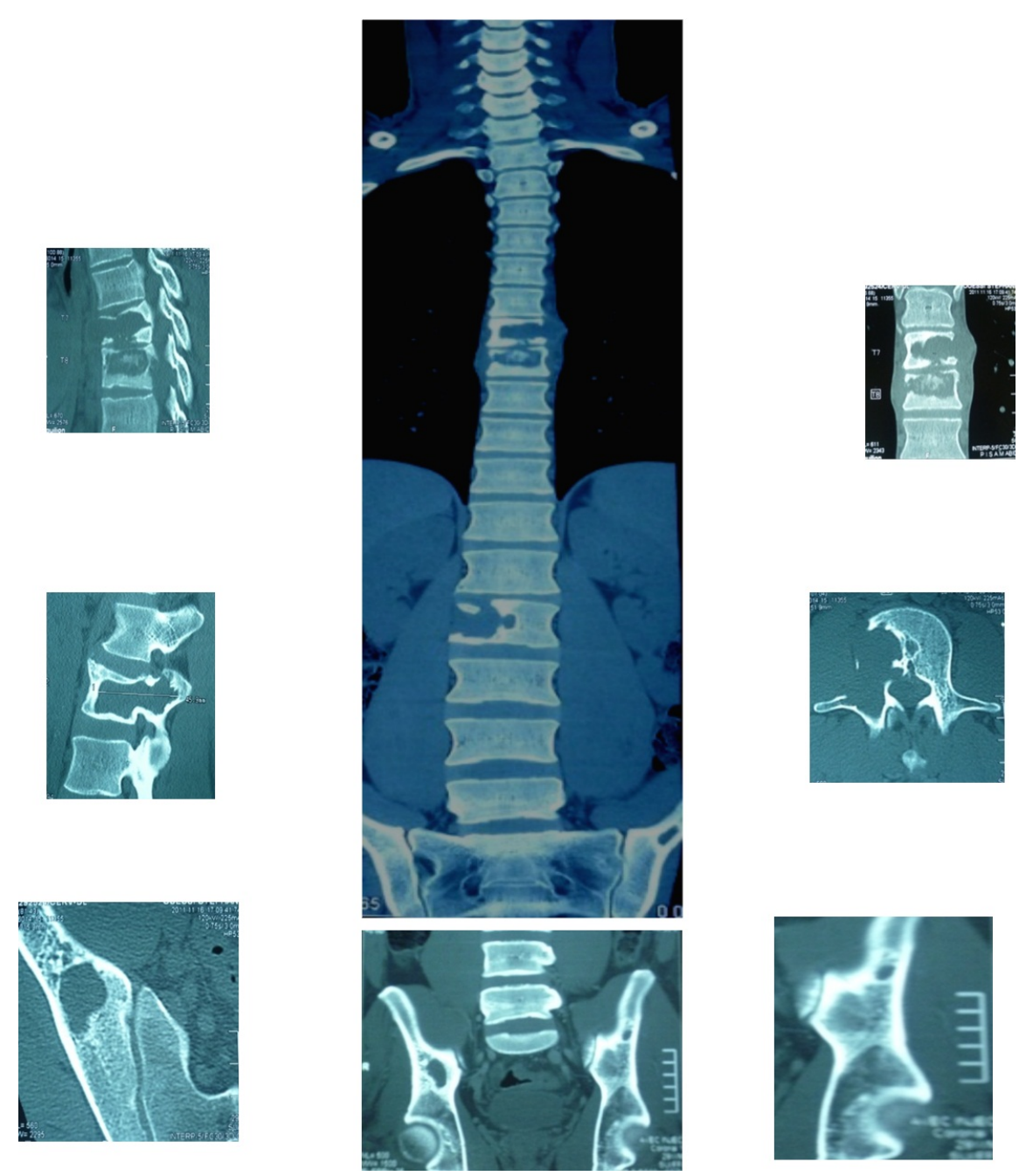

Figure 1. Skeletal CT Scan showing osteolystic lesion caused by mycobacterium tuberculosis.

area of $\mathrm{TB}$, the cultures and stains of this initial specimen were negative. A month later the patient developed an acute spinal cord compression syndrome. Neurologic examination demonstrated a 0/5 flaccid paraplegia. Professional counselling was provided and the patient expectations about the likelihood of recovery, if any, were addressed. Emergency decompression surgery was warranted to stop spinal cord suffering and carry out direct biopsy of spinal lesions. The surgery was performed on January $5^{\text {th }} 2013$ and demonstrated a purulent epidural abscess and osteolysis. Biopsy of spinal lesions was undertaken. The pathological examination was in favor of tuberculosis (Figure 3). Despite surgical stabilization and cementoplast, anti-TB therapy and kinesitherapy, the patient was still significantly limited a few months later with a $0 / 5$ flaccid paraplegia. TB infection was cleared at the end of the two-phase regimen. The patient sought legal advice and sued the hospital for negligence because to his legal team, it is the hospital legal responsibility to acquire adequate equipment to avoid delayed diagnosis and treatments. 

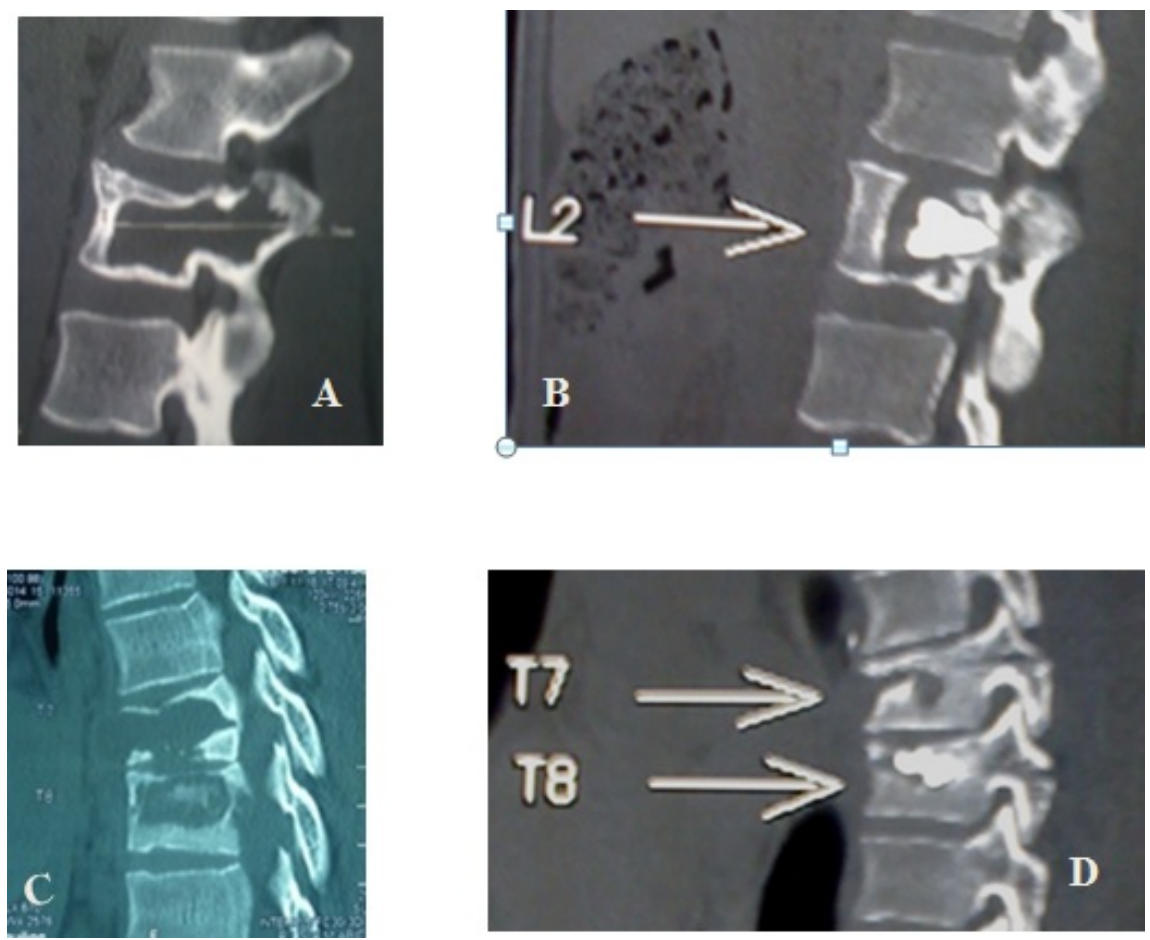

Figure 2. Post vertebroplasty CT Scan control. There is not enough cement in te cavities.

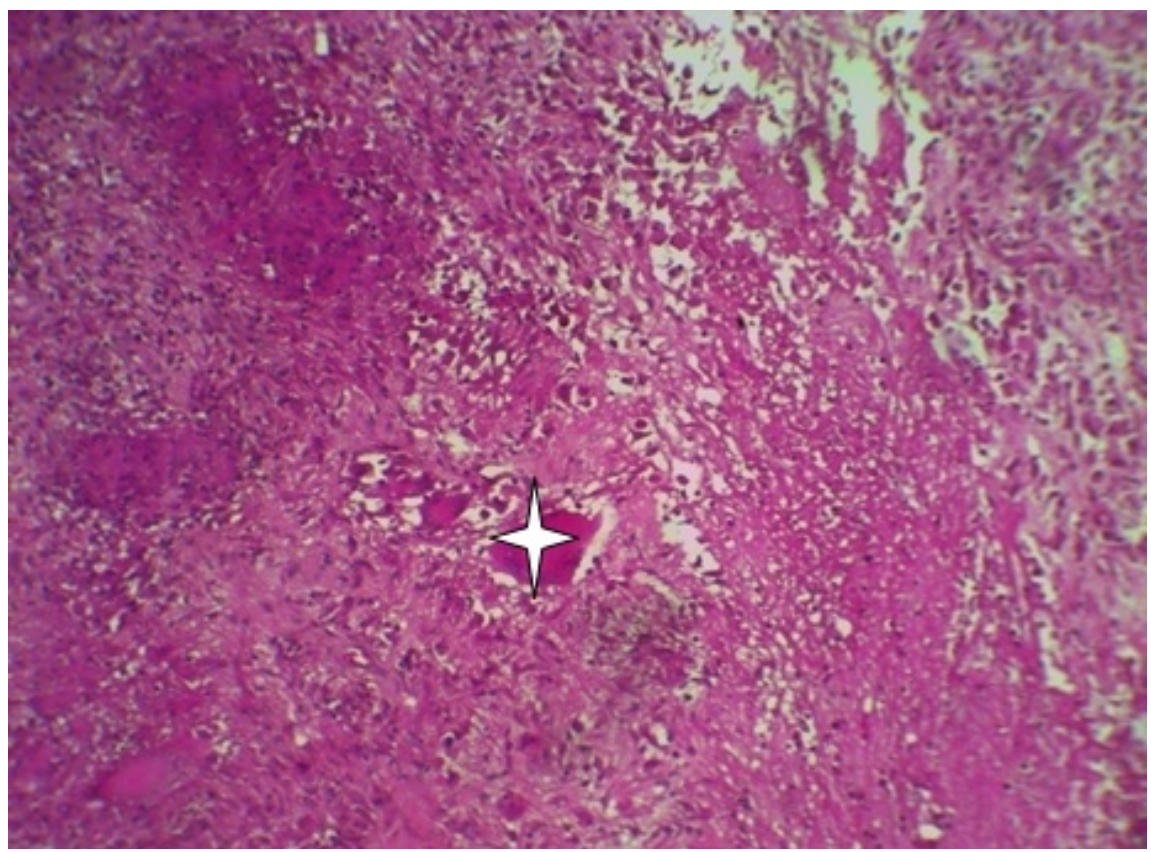

Figure 3. (HEX100) Histologic examination of resected infectious tissue $\left(p^{\prime}\right)$ revealing granulomatous inflammation with caseous necrosis and typical multinucleated giant cells.

\section{Discussion}

Several cases of extensive spinal tuberculosis have been reported [2] [4]-[13]. In most series, cervical, thoracic and lumbar spines have been equally affected. There are three reasons why this present case is relevant. 
The first reason is the place of CT scan in the diagnosis of mutifocal skeletal tuberculosis.A few cases reported in the literature have hinged on the fact that multifocale skeletal tuberculosis diagnosis remains difficult. The clinical picture is that ofinsidious onset with no relevant medical history or physical signs. In light of the present case, osteoarticular tuberculosis must be considered in patients with insidious musculoskeletal symptomatology. Our detailed Medline database search revealed that multifocal osteoarticular tuberculosis, unlike other forms of extra-pulmonary tuberculosis, is not associated with HIV infection. Differential diagnosis are tumors, metastasis, malignant lymphoma or multiple myeloma, other infections such as bone localization of histoplasmosis, vertebral histoplasmosis mimicking tuberculosis spondylodiscitis in the context of rheumatoid arthritis [6] [14] [15] [16] [17] [18]. Histoplasmosis is very difficult to be differentiated clinically, radiologically and microbiologically from tuberculosis. Other spondylitis or spondylodiscitis especially those caused by brucellosis are similar to the tuberculosis. Clinically, the evolution of the disease is insidious and imaging studies show collapsed vertebral body in approximately $5 \%$ of all cases of skeletal Tuberculosis [19] [20] [21]. The diagnosis of multifocal skeletal tuberculosis is frequently delayed due to its rarity and non specific symptoms [9] [18]. Tuberculous spondylitis must be differentiated from those caused by a non-specific germ [22] [23]. Difficulties in diagnosis often lead to delayed treatment with devastating consequences for patients [12].

The second reason is a potential role that vertebroplasty could have played in spreading spinal lesions. The extant medical literature is crowded with seminal works claiming to have observed a direct link or indeed a close relationship between vertebroplasty and the spreading of TB lesions involving the spine [22][28]. Our patient underwent cementoplasty following an acute spinal cord compression syndrome. After a two-phase TB-therapy the TB infection was cleared and the hypothesis that vertebroplasty could have spread spinal TB lesions became indefensible. Kang et al. concluded that, given the controversies surrounding the relationship between vertebroplasty and spinal TB, misdiagnosis or complications should be discussed instead [29].

The third reaon is the treatment of spinal tuberculosis [3] [12] [13]. Surgical treatment of spinal tuberculosis is controversial, because of a good understanding of $\mathrm{TB}$ drug resistance alongside newer modalities of spinal instrumentation. Indications for surgery need to be redefined in this context. Typical initial treatment includes a 9-month, two-phase combination therapy with four drugs (Isoniazid, Rifampin, Pyrazinamid, Ethambutol or Streptomycin) because of the above reasons. Partial synovectomy and other surgical procedures should be restricted to joints with severe cartilage destruction, large abscesses, joint deformity, multiple drug resistance, or atypical mycobacteria. Our patient benefitted from a vertebroplasty procedure. In any doubt, treatment should be tailored based on physician's own experience and individual patient's needs so to maximize the chances of recovery. It is the author's view that more cement might be needed in vertebroplasty for spinal tuberculosis. 


\section{Conclusion}

Multifocal skeletal tuberculosis must be considered in patients with insidious musculoskeletal symptomatology. Tuberculosis should be the first differential diagnosis of multiple destructive bone lesions especially in patients from regions where tuberculosis is endemic. Our detailed medline database search revealed that multifocal osteoarticular tuberculosis, unlike other forms of extra-pulmonary tuberculosis, was not associated with HIV infection. Several cases of spinal tuberculosis thought to have been spread by vertebroplasty have been reported in the extant medical literature. But the scientific evidence to support such relationship is very controversial. Further research will have to be carried out to establish whether or not previous observations are misdiagnosis or just dreadful complications. Patient selection for kyphoplasty should be robust when there is a history of focal or systemic TB infection. The clinical picture of spinal TB is often nonspecific, and clinicians should be aware of this entity. Actively investigating TB with microbiological and histologic examination is paramount so to avoid any delay in diagnosis and treatment. It is the author's view that tuberculous spondylodiscitis in adults can be well managed conservatively in the vast majority of cases, and indications for surgery are few and should be specific.

\section{Acknowledgements}

There is no conflict of interest for any of the authors.

\section{References}

[1] Moon, M.-S. (2014) Tuberculosis of Spine: Current Views in Diagnosis and Management. Asian Spine Journal, 8, 97-111.

[2] Moon, M.-S. (2006) Development in the Management of Tuberculosis of the Spine. Curr. Orthop., 20, 132-140.

[3] Moon, M.-S. (2007) Tuberculosis of Spine-Contemporary Thoughts on Current Issues and Perspective Views. Current Orthopaedics, 21, 364-379. https://doi.org/10.1016/j.cuor.2007.09.006

[4] Marudanayagam, A. and Gnanadoss, J.J. (2006) Multifocal Skeletal Tuberculosis: A Report of Three Cases. The Iowa Orthopaedic Journal, 26, 151-153.

[5] Turgut, M. (2001) Multifocal Extensive Spinal Tuberculosis (Pott's Disease) Involving Cervical, Thoracic and Lumbar Vertebrae. British Journal of Neurosurgery, 15, 142-146. https://doi.org/10.1080/02688690120036856

[6] Amogne, W. and Abubaker, A. (2002) Multifocal Vertebral Tuberculosis with the Involvement of the Ribs Case Report. Ethiopian Medical Journal, 40, 397-405.

[7] Yilmaz, M.H., Kantarci, F., Mihmanli, I. and Kanberoglu, K. (2004) Multifocal Skeletal Tuberculosis. Southern Medical Journal, 97, 785-787.

[8] Emel, E., Güzey, F.K., Güzey, D., Bas, N.S., Sel, B. and Alatas, I. (2006) Non-Contiguous Multifocal Spinal Tuberculosis Involving Cervical, Thoracic, Lumbar and Sacral Segments: A Case Report. European Spine Journal, 15, 1019-1024. https://doi.org/10.1007/s00586-005-0989-0

[9] Hong, L., Wu, J.G., Ding, J.G., Wang, X.Y., Zheng, M.H., Fu, R.Q., Li, W.B., Peng, W.X., He, W.F. and Sun, Q.F. (2010) Multifocal Skeletal Tuberculosis: Experience in Diagnosis and Treatment. Médecine et Maladies Infectieuses, 40, 6-11. 
https://doi.org/10.1016/j.medmal.2009.03.004

[10] Haider, N., Aziz, M., Khan, A.Q. and Zulfiqar, M. (2011) Tubercular Dactylitis and Multifocal Osteoarticular Tuberculosis-Two Rare Cases of Extrapulmonary Tuberculosis. BMJ Case Reports. https://doi.org/10.1136/bcr.09.2011.4800

[11] Kim, J.-H., Kim, S.-H., Choi, J.-I. and Lim, D.-J. (2014) Atypical Noncontiguous Multiple Spinal Tuberculosis: A Case Report. Korean Journal of Spine, 11, 77-80. https://doi.org/10.14245/kjs.2014.11.2.77

[12] Patil, S.S., Mohite, S., Varma, R., Bhojraj, S.Y. and Nene, A.M. (2014) Non-Surgical Management of Cord Compression in Tuberculosis: A Series of Surprises. Asian Spine Journal, 8, 315-321. https://doi.org/10.4184/asj.2014.8.3.315

[13] Moon, M.-S. (2014) Tuberculosis of Spine: Current Views in Diagnosis and Management. Asian Spine Journal, 8, 97-111. https://doi.org/10.4184/asj.2014.8.1.97

[14] Tsay, M.H., Chen, M.C., Jaung, G.Y., Pang, K.K. and Chen, B.F. (1995) Atypical Skeletal Tuberculosis Mimicking Tumor Metastases: Report of a Case. Journal of the Formosan Medical Association, 94, 428-431.

[15] Musoke, F. (2001) Spinal African Histoplamosis Simulating Tuberculous Spondylitis. African Health Sciences, 1, 28-29.

[16] Jahng, J., Kim, Y.H. and Lee, K.S. (2007) Tuberculosis of the Lower Lumbar Spine with an Atypical Radiological Presentation-A Case Mimicking a Malignancy. Asian Spine Journal, 1, 102-105. https://doi.org/10.4184/asj.2007.1.2.102

[17] De Morais, S.S., MafraMde, O., Canterle, E.M., de Lima, L.L. and Ribeiro, S.L. (2008) [Histoplasmosis Mimicking Tuberculosis Spondylodiscitis in a Patient with Rheumatoid Arthritis]. Acta Reumatológica Portuguesa, 33, 360-363.

[18] Go, S.W., Lee, H.Y., Lim, C.H., Jee, W.H., Wang, Y.P., Yoo, I.R. and Kang, J.Y. (2012) Atypical Disseminated Skeletal Tuberculosis Mimicking Metastasis on PETCT and MRI. Internal Medicine, 51, 2961-2965. https://doi.org/10.2169/internalmedicine.51.8347

[19] Kim, D.-H. and Cho, Y.-D. (2008) A Case of Spondylodiscitis with Spinal Epidural Abscess Due to Brucella. Journal of Korean Neurosurgical Society, 43, 37-40. https://doi.org/10.3340/jkns.2008.43.1.37

[20] Bouaziz, M.C., Bougamra, I., Kaffel, D., Hamdi, W., Ghannouchi, M. and Kchir, M.M. (2010) Noncontiguous Multifocal Spondylitis: An Exceptional Presentation of Spinal Brucellosis. La Tunisie Medicale, 88, 280-284.

[21] Ekici, M.A., Özbek, Z., Kazanc1, B. and Güçlü, B. (2014) Collapsed L4 Vertebral Body Caused by Brucellosis. Journal of Korean Neurosurgical Society, 55, 48-50. https://doi.org/10.3340/jkns.2014.55.1.48

[22] Schofer, M.D., Lakemeier, S., Peterlein, C.D., Heyse, T.J. and Quante, M. (2011) Primary Pyogenic Spondylitis Following Kyphoplasty: A Case Report. Journal of Medical Case Reports, 5, 101. https://doi.org/10.1186/1752-1947-5-101

[23] Schmid, K.E., Boszczyk, B.M., Bierschneider, M., Zarfl, A., Robert, B. and Jaksche, H. (2005) Spondylitis Following Vertebroplasty: A Case Report. European Spine Journal, 14, 895-899. https://doi.org/10.1007/s00586-005-0905-7

[24] Bouvresse, S., Chiras, J., Bricaire, F. and Bossi, P. (2006) Pott's Disease Occurring after Percutaneous Vertebroplasty: An Unusual Illustration of the Principle of Locus Minoris Resistentiae. Journal of Infection, 53, e251-e253. https://doi.org/10.1016/j.jinf.2006.02.014

[25] Ivo, R., Sobottke, R., Seifert, H., Ortmann, M. and Eysel, P. (2010) Tuberculous Spondylitis and Paravertebral Abscess Formation after Kyphoplasty: A Case Report. Spine, 35, E559-E563. https://doi.org/10.1097/BRS.0b013e3181ce1aab 
[26] Chen, Y.J., Chen, H.Y. and Hsu, H.C. (2010) Re: Ivo R, Sobottke R, Seifert H, et al. Tuberculous Spondylitis and Paravertebral Abscess Formation after Kyphoplasty: A Case Report. Spine, 35, E1360-E1361.

[27] Kim, H.J., Shin, D.A., Cho, K.G. and Chung, S.S. (2012) Late Onset Tuberculous Spondylitis Following Kyphoplasty: A Case Report and Review of the Literature Korean. Korean Journal of Spine, 9, 28-31.

[28] Ivo, R., Sobottke, R., Seifert, H., Ortmann, M. and Eysel, P. (2010) Tuberculous Spondylitis and Paravertebral Abscess Formation after Kyphoplasty: A Case Report. Spine, 35, E559-E563.

[29] Kang, J.H., Kim, H.-S. and Kim, W.S. (2013) Tuberculous Spondylitis after Percutaneous Vertebroplasty: Misdiagnosis or Complication? Korean Journal of Spine, 10, 97-100. https://doi.org/10.14245/kjs.2013.10.2.97

Submit or recommend next manuscript to SCIRP and we will provide best service for you:

Accepting pre-submission inquiries through Email, Facebook, LinkedIn, Twitter, etc. A wide selection of journals (inclusive of 9 subjects, more than 200 journals)

Providing 24-hour high-quality service

User-friendly online submission system

Fair and swift peer-review system

Efficient typesetting and proofreading procedure

Display of the result of downloads and visits, as well as the number of cited articles Maximum dissemination of your research work

Submit your manuscript at: http://papersubmission.scirp.org/

Or contact ojmn@scirp.org 